\title{
Обычаи избегания в традиционной семье коренных народов Нижнего Амура и Сахалина: середина XIX - начало XX вв.
}

Заявленная в статье проблема представляется актуальной с точки зрения современной демографической ситуации и поиска путей её улучшения, когда люди обращаются к своим истокам с целью понять, как их предки сосуществовали раныше, с помощью чего им удавалось сохранить крепкую и дружную семью. Помимо этого, данное исследование представляет собой комплексный сравнительно-сопоставительный анализ указанной проблемы практически между всеми родственными категориями традиционной семьи коренных этносов Нижнего Амура и Сахалина.

Воспитание детей у коренных народов Нижнего Амура и Сахалина (удэгейцев, нанайцев, тазов, ульчей, нивхов, орочей, негидальцев, эвенков, уйльта (другие этнонимы: "ороки", "ульта", "орочоны") обусловливалось в первую очередь тем, что мужчины в родовом обществе были главенствующим и постоянным элементом рода, а женщины - подчинённым и переменным. Девочек с раннего детства приучали к тому, что они "чужеродки" и после замужества уйдут в другой род; это накладывало отпечаток на взаимоотношения внутри семьи. Воспитание братьев и сестёр преследовало одну цель - отдалить их друг от друга, разобщить. Их приучали к тому, что они будут жить отдельно, поэтому надо стесняться друг друга и не привыкать друг к другу. Детей при помощи запретов приучали к издревле установившемуся разделению труда между полами. Мальчикам запрещалось играть с орудиями труда женщин, а девочкам - с орудиями труда мужчин, из-за опасности потери этими предметами промысловых и хозяйственных свойств [7, с. 29; 18, с. 171]. По половому признаку строго различалась даже посуда. Например, в тазике, в котором негидальцы и нивхи купали мальчика, запрещалось стирать девичьи и женские вещи, иначе мальчик станет трусливым и слабым, как женщина (Рукопись Фадеевой Е.В. Из архива автора). В родовом обществе имелись специальные термины, характеризующие отношения между близкими родственниками со стороны отца, препятствующие их близкому общению (например, нивх. "ланьнт" - стесняться, избегать друг друга). Этим обычаем взаимного избегания охватывались отношения между братьями и сёстрами, между старшими братьями и жёнами младших братьев, между свёкром и невестками [20, с. 356; 8, с. 265]. Брат с сестрой (как правило, старшей) не могли разговаривать, шутить, играть друг с другом, смотреть друг на друга. При встрече вне дома они обходили один другого на расстоянии. Нивхи считали разговор с младшими сёстрами равносильными половому общению с ними. Брату категорически запрещалось близко подходить к сестре, класть голову ей на колени для туалета головы, поскольку поиск головных вшей являлся важным элементом социальных, можно даже сказать, интимных отношений, которые были возможны только либо между родителями и детьми, либо между супругами. Помимо этого, ему было запрещено курить вместе с ней одну трубку, есть одновременно с сестрой с одного столика, называть её по имени [8, с. 67]; (Архив ОИАК. Ф. В.К. Арсеньева. Оп. 1. Д. 11. Л. 131). Брат к сестре мог обратиться либо косвенно, как к третьему лицу, либо на "Вы". При встрече на улице сестра отворачивалась от брата в сторону и уступала ему дорогу. Старшие братья, заметив младших сестер, предупреждали девочек о своем присутствии покашливанием $[14$, с. 219]. У нанайцев сестра не имела права называть старшего брата по имени, как и младший брат старшую сестру

(C) Фадеева E. B., 2020

ФАДЕЕВА Елена Викторовна, канд. ист. наук, старший научный сотрудник отдела этнографии, этнологии и антропологии Института истории, археологии и этнографии народов Дальнего Востока ДВО РАН (2. Владивосток). E-mail: ev_fadeeva@mail.ru 
(Архив МАЭ РАН. Ф. К-2. Оп. 1. Д. 217. Л. 53). В остальном отношения между младшей сестрой и старшим братом строго не регламентировались; у орочей сестра участвовала в общей трапезе с братом (Архив ОИАК. Ф. В.К. Арсеньева. Оп. 1. Д. 10. Л. 79) ${ }^{1}$. У ороков влияние церкви сказывалось на большей свободе девушек в детском возрасте. Исчезающая старая прежняя классификация родства всё меньше стояла помехой к тому, чтобы девочки лет 8-10 свободно играли со своими родными и двоюродными (со стороны отца) братьями. Но ещё в начале XX в. брат с сестрою избегали разговора, что некогда было обязательным правилом. После долгих лет разлуки родная сестра не имела права поцеловать брата в виде приветствия. Мужчины с мужчинами и женщины с женщинами в таких случаях целовались, равным образом и родители с детьми. В обычных случаях жизни поцелуй имел место только по отношению к детям [13, с. 21-22].

Несмотря па суровые регламентации отношений братьев и сестер между собой у ороков имелись предания о случаях кровосмешения. Так, еще в XVII в. орок по имени Тудаська имел сношения со своей сестрой. Когда люди убедились в этом, то все от них отступились и выгнали их из дому, принуждая жить одним по лесам. Предполагают, что они вскоре погибли. Подобное изгнание из своей среды и оставление людей на верную гибель было, очевидно, наказанием за грехи, неподдающиеся искуплению [13, с. 23]. Таким образом, обычаи избегания отделяли братьев от сестёр в роде и устанавливали определённые нормы поведения между ними.

Обычаи избегания распространялись и на сестёр. Так, у нанайцев считалось, что в доме своего отца две замужние сестры не должны есть за одним столиком и из одной посуды (Архив МАЭ РАН. Ф. 5. Оп. 2. Д. 65. Л. 36) ${ }^{2}$.

У народов Нижнего Амура, младший брат не только имел супружеские права на жену своего старшего брата (в отсутствие последнего), но и мог с ней свободно общаться, шутить, курить из одной трубки, есть вместе с ней. Мужчина вне своего рода имел право на половое общение с сёстрами своей жены, а также с сёстрами жён всех своих старших (но не младших) братьев. Старшему брату с женой младшего всё это, за исключением делового разговора, было запрещено. При этом говорящий обращался к запретному лицу в третьем лице и говорил "в пространство". Существование запретов позволяло предотвратить половое общение в запрещённых степенях, ссоры из ревности в случаях дозволительного общения.

По тому, как мужчины и женщины общались между собой, можно было определить степень родства между ними. Чем суше и строже были эти отношения, тем ближе было их родство. Мужчина, впервые встретившись с женщиной, сначала выяснял её родословную и, в случае попадания её в запрещённые для него категории женщин, знакомство тут же прекращал. У орочей шутки дозволялись только с женщинами из рода матери и возбранялись с женщинами из рода отца. С женщинами из одного с ними рода мужчины никогда не заигрывали и не шутили, тогда как с "дозволенными" женщинами они вели себя достаточно фривольно (Архив ОИАК. Ф. В. К. Арсеньева. Оп. 1. Д. 11. Л. 49, 131). Женщины-нанайки с дозволенными мужчинами вели себя свободно: смеялись, отвечали на их любезности. Женщины никогда сами не навязывались мужчине, но, если мужчина просил их о благосклонности, то ему никогда не отказывали, но денег и подарков никогда за это не брали. Женщина могла сама заигрывать с понравившимся ей мужчиной (Архив МАЭ РАН. Ф. 5. Оп. 2. Д. 80. Л. 4). У нанайцев замужним женщинам не разрешалось смотреть на чужих мужчин и разговаривать с ними [10, с. 164, 182-183]; (Архив МАЭ РАН. Ф. 5. Оп. 2. Д. 80. Л. 3). У нивхов мужчины и женшины из одного рода не могли разговаривать, шутить, и смотреть друг на друга [20, с. 188].

Избегания между будущими супругами начинались только с момента сватовства: жених не виделся с невестой во время сватовства, помолвки, переговоров о калыме. У нанайцев невеста при встрече с женихом избегала его, а в случаях появления последнего в доме её отца пряталась от него [19, c. 10-11;

1 Архив ОИАК - Архив Общества изучения Амурского края.

2 Архив МАЭ РАН - Архив Музея антропологии и этнографии РАН. 
10, с. 150]. Ещё до помолвки, во время третьего визита семьи жениха, невеста пряталась одетая во всё лучшее в чужих франзах. Вообще в брачных церемониях невеста играла пассивную роль, с момента просватывания она обычно ограничивалась обществом близких подруг и женской родни, занимаясь приготовлением приданого. Тем не менее избегания между женихом и невестой не мешали их тайным свиданиям $[6$, с. 170-171, 196]. Во время свадебного пира в доме невесты жених с невестой вели себя скромно: сидели рядом, ели из одной чашки, курили одну трубку, но не разговаривали друг с другом и даже не оставались наедине [20, с. 282]. На другой день молодожёны уже без стеснения разговаривали между собой и с людьми, вместе ходили в гости и называли друг друга мужем и женой [16, с. 137]. Половая близость между женихом и невестой до свадьбы запрещалась - при нарушении запрета могли наказать духи. Интимные отношения между ними были возможны лишь после окончания двух - трёхдневного торжества, когда жених приводил невесту к себе домой [1, с. 201]. Невеста также "скрывалась" не только от жениха, но и от его родителей, братьев, сестёр и других родственников. Так, например, у тазов, свекровь, главная хозяйка дома, во время свадебного пира ела отдельно за низеньким столиком на кане, тогда как молодая жена садилась за общий стол, сама себе наливала и ела. Затем помогала по хозяйству: мыла посуду, убирала со стола, подметала пол. Приблизительно неделю она не работала на огороде, но выполняла мелкую домашнюю работу. Помимо этого, во время свадебного ритуала замужняя женщина чюй чил проа, на правах старшей, советовала новобрачной слушаться во всем свекровь, которая будет играть большую роль в её последующей жизни, не забывать, что дом, в который она вошла, чужой. Невеста всё это должна была выслушивать молча [5, с. 264, 265].

К членам семьи невестка относилась согласно установленным обычаям: с младшими она держалась как старшая: называла их по личным именам, распоряжалась ими и шутила с ними; со старшими мужчинами она вела себя сдержанно, не называла их по именам, не глядела на них. Невестка никогда не называла по имени ни свекровь, ни старших сестёр мужа, даже в их отсутствие, а также и после их смерти. С ними она могла вести только деловые разговоры, то есть, выслушивать их советы и приказания, тогда как психологическое общение исключалось [20, с. 188]. Невестка не могла показаться свёкру с голыми ногами и непокрытой головой, не могла сидеть, повернувшись к свёкру спиной. Она лишь отвечала на вопросы шёпотом или кивком головы, либо через младших членов семьи. Лишь с появлением ребёнка невестка становилась более самостоятельной в рамках семьи $[20$, с. $189 ; 6$, с. 174-180]; (Рукопись Фадеевой Е.В. Из архива автора). От неё требовалось уважение, особенно к матери мужа [20, с. 188]. Дружественные и нестеснённые отношения устанавливались между невесткой и младшими представителями семьи мужа женского пола, которым тем не менее запрещалось называть её имя (Архив МАЭ РАН. Ф. К-2. Оп. 1. Д. 217. Л. 50); [6, с. 183-184]. Свобода отношений со старшими свойственницами мужа объясняется совместным ведением хозяйства, номенклатурой родства, по которой они считались сёстрами. Женщине нельзя было целовать в щеки мужа, отца, мать и всех родственников старше себя. Однако, под влиянием русских, молодожены, не стесняясь посторонних, могли целоваться, а муж мог взять жену на руки, чего раньше делать было нельзя [17, с. 193-194].

Определённые правила общения существовали и в поведении женщин между собой, которое зависело от возраста и положения в семье и роде. Так, если женщина принадлежала к числу старших, то она пользовалась авторитетом, говорила и отдавала распоряжения. Если она относилась к разряду младших, то говорила тихим голосом, не глядя на старшего собеседника. Но на совместном чаепитии они разговаривали как равные: шутили между собой, иногда пели. В зависимости от личности женщины различалось и её поведение. Многие из них были очень ласковыми и женственными; другие - склонными к сплетням и болтовне; третьи - нахальными и грубыми (Архив МАЭ РАН. Ф. К-2. Оп. 1. Д. 217. Л. 198, 204-205). Для дочери слово матери было законом. При посторонних мужчинах нанайские девушки особого стыда не испытывали, но при чужих женщинах часто испытывали смущение (Архив МАЭ РАН. Ф. 5. Оп. 2. Д. 80. Л. 1). Зять в период от помолвки до свадьбы 
избегал старших родственников жены. Мужчина не мог вести прямой разговор с матерью своей жены и с родителями своего тестя, когда того не было дома [9, с. 232]. Избегание тестя со стороны зятя объясняли обычаем мнимого похищения, поскольку в этом случае он не являлся братом матери. По этой же причине нивх свою невесту, взятую не из рода его матери, называл термином cox, означающую запретную в половом отношении категорию [20, c. 48]. С младшей сестрой жены, согласно нормам группового брака, он мог разговаривать, шутить и иметь половые отношения.

Таким образом, запреты отражали ограниченные отношения между восходящими и нисходящими линиями родства в традищионном обществе, касающиеся как женщин, так и мужчин.

В семье между супругами также существовали определённые ограничения, призванные подчеркнуть превалирующее положение мужчин. Мужчина называл свою жену её личным именем, тогда как жена использовала термины "муж", "хозяин", а после рождения ребёнка - отец такого-то ребёнка (Архив МАЭ РАН. Ф. 5. Оп. 4. Д. 32. Л. 5). Жена не смела разговаривать с мужем при старших родственниках или в присутствии посторонних мужчин (в первые годы замужества), не могла открыто проявлять своё внимание и заботу о муже, не могла есть с мужчинами за одним столом. Стоит отметить, что старые обычаи в традиции приема пищи женщинами после мужчин проявлялись вплоть до середины прошлого века, и теперь это иногда имеет место в семьях пожилых супругов [15, с. 112]. Муж не мог носить жену на руках по стойбищу, в противном случае о нем, надсмехаясь, говорили: "Вот так охотник, женщина на нем верхом едет. Какой это охотник?". Мужчину, носящего в дом воду, колющего дрова, при наличии в доме здоровой жены, называли бабой и считали уронившим честь охотника. Также считалось грехом сильно любить жену, любоваться ею, бояться отойти от нее. По этому поводу даже существовала примета, что, если муж с женой сильно льнули друг к другу, они, тем самым, предугадывали скорую разлуку, возможно, даже смерть одного из супругов $[17$, с. $149,187-188]$. У ороков муж с женой никогда не целовались при других или днем; считая, как, впрочем, все народы на Востоке, что ласка эта слишком интимная и потому должна быть укрыта от ненужных свидетелей [13, с. 21-22]. Подобные ограничения связывают с тем, что молодые долгое время жили вместе со старшими родственниками мужа, что и накладывало отпечаток на их взаимоотношения.

Прощание с женами перед уходом на промысел проходило коротко: один охотник, например, требовал от старшей жены беречь молодую жену, второй прижимал к груди заплаканное лицо своей беременной жены. Провожать охотников, как и встречать, надо было с радостными улыбками и приподнятым настроением. Женщина встречала мужа на берегу реки, ухватив за нос оморочку, подтягивала ее на песок. Затем она, вместе с детьми, заносила в дом мясо, шкуры, охотничье снаряжение. Встреча проходила сдержанно, жена при этом не задавала мужу никаких вопросов, так как на это у них не было права, и немедленно начинать готовить ему еду. Однако многие из них по лицам охотников, по их поведению точно определяли, сопутствовала ли их мужьям удача или обходила стороной $[17$, с. $221,193,161,291]$. Ряд запретов для женщин в доме охотника существовал до 1970-х годов. Женщины по-прежнему не должны были перешагивать через орудия охоты; жена охотника не должна была класть свою одежду на одежду мужа и т.д. [3, с. 90]. На улице женщина всегда шла позади мужа, не смея забегать вперёд. В целом же супруги практически никогда не вмешивались в дела друг друга.

Если в доме появлялся гость, то роль женщины сводилась лишь к приготовлению угощения, чаще ей не разрешалось даже находиться в доме. Нанайка, при появлении посторонних мужчин, поворачивалась лицом к стене или забивалась в дальний угол франзы, либо опускала не только глаза, но и голову. Если пришедший садился близко к женщине, она тут же переходила на другое место. Отвечала женщина только на самые необходимые вопросы, не поднимая при этом на собеседника глаз [10, с. 170].

Нельзя было женщинам и петь в присутствии мужчин, тогда как последние делали это совершенно свободно. Если кто-то из мужчин случайно становился свидетелем женского пения, сразу же поднимал ругань, и дело 
зачастую заканчивалось избиением певуньи. И.А. Лопатин видел причину такого ограничения в излишней фрривольности содержания женских песен, в которых женщины описывали своих страстных возлюбленных, при этом все вещи назывались своими именами и со всеми подробностями. Тем не менее женщины часто пели, оставаясь наедине дома или уходя в лес за дровами, выражая через песни свою тоску по свободе, непринуждённой любви и неподневольных ласках, которых они были лишены в обычной жизни [10, с. 345]. Однако современные негидалки считают, что петь постоянно нельзя (Архив ИИАЭНДВ ДВО РАН. Ф. 1. Оп. 2. Д. 599. Т. 2. Л. 223) ${ }^{3}$.

Мужчины и женщины старались не касаться орудий труда друг друга, чтобы те не потеряли свои промысловые качества. Нанайским женщинам категорически запрещалось надевать мужскую обувь, иначе у мужчин, якобы, ослабеют колени, мышцы, и они не смогут нормально ходить [12, с. 55].

Женская кровь всегда представлялась вещью могущественной и опасной, из-за чего вся жизнь женщины распадалась как бы на три периода: деторождение; период менструации и период, когда менструация прошла, и женщина лишь частично находилась под запретом. В связи с этим ей приходилось постоянно выполнять различные запреты, которые варьировались в зависимости от того, в каком положении она находилась в данный момент. Такие физиологические особенности организма женщины также накладывали свой отпечаток на её модель поведения.

Так, всем женщинам запрещалось садиться под "помещением" для духов, на почетное место в жилище - "лалу"; ей не позволялось ездить на лошадях или оленях, а также быть собственницей этих животных, так как они иногда выступали посредниками между людьми и духами. Эти запреты имели магическую окраску, поскольку были связаны с представлениями о разных духах, вселяющихся в мужчин и женщин.

На менструирующих женщин налагались табу, касающиеся охоты и рыбной ловли, для того, чтобы не спугнуть запахом крови чуткого зверя и не отвести удачу от охотника. Помимо этого, им запрещалось сидеть на ещё не вполне обработанной шкуре, употреблять в пищу мясо тигра и медведя, и т.д. Менструирующим женщинам, также как и роженицам, запрещалось мыться в реке или мыть там грязное бельё. За такой грех бог Ендури мог сурово покарать грешницу, как это случилось, например, с героиней нанайского сказания Хорари - Елбуси - Хани, которой Ендури через дракона Мудура рассёк голову $[19$, c. 4]. У удэгейцев женщины во время месячных, как и во время родов, находились в отдельном шалаше, чтобы кровь не попала на мужчину или его орудия труда (Рукопись Фадеевой Е.В. Из архива автора). У нанайцев менструирующие женщины не смели и близко подходить к амбару, где хранилось продовольствие, а по углам стояли сундуки с охотничьим снаряжением и одеждами, которые мужчины надевали только в тайге, чтобы к ним не прикасались женские руки. Самой плохой приметой у них считалось, если "грязная" женщина поднималась в амбар, под которым в это время оказывался охотник; последнего, в этом случае, будут преследовать неудачи на промысле, поскольку звери не будут допускать его близко к себе $[17, \mathbf{c .} 68,149]$.

Беременные женщины, а также роженицы, еще не прошедшие после родов обряда очищения, не могли присутствовать при каком-либо жертвоприношении или шаманском обряде; нельзя было им вступать и в половые сношения ни со своим мужем, ни с другими мужчинами. Помимо этого, чтобы уберечь от стресса, беременных и рожениц не пускали на похороны. Так, по представлениям, например, нанайцев, беременность женщины негативно влияла на охотничью удачу. Отрицательное поле, которым, якобы, обладали женщины в этот период, могло опосредованно - через вещи - оказать воздействие на результаты промысла. Поэтому беременной женщине запрещалось шить одежду и обувь для охотника, особенно отправляющегося на соболя. Если же по какой-либо причине орудия и снаряжение оказывались в помещении, где произошли роды, то считалось, что они прикоснулись к крови. В этом случае рукавицы, чулки, обувь, одежду следовало поменять, иначе охотник не встретит в лесу зверей. Горинские нанайцы были уверены, что в этом случае

3 Архив ИИАЭНДВ ДВО РАН - Архив Института истории, археологии и этнографии народов Дальнего Востока ДВО РАН. 
неудачи будут преследовать человека целый год. Шаманкам, находящимся "в положении" или в периоде менструащии, запрещалось общаться с какими-либо духами, а, следовательно, - шаманить. Этот запрет для последней соблюдался все 9 месяцев [2, с. 47; 4, с. 98].

Все эти запреты были направлены на то, чтобы нейтрализовать чуждых для рода мужа духов жены. Женщина в течение всей своей жизни оставалась под покровительством её собственных духов. Благодаря этому замужняя женщина во многих случаях подвергалась табу. Недружелюбное отношение к женщине на самом деле означало лишь то, что для мужчин она находилась в состоянии табу. Вступая в семью мужа, женщина приносила с собой своих собственных духов, которые могли явиться источником всевозможных осложнений для родственников мужа. И если получалось, что духи жены оказывались виновными в каких-либо затруднениях последних, то жене приходилось особенно усердно соблюдать все наложенные на неё запреты и правила (Архив МАЭ РАН. Ф. К-2. Оп. 1. Д. 214. Л. 38, 40, 42). Таким образом, люди избегали женщину не вследствие её подчиненного положения, а для того, чтобы уйти от зловредной деятельности её духов.

Отец, согласно обычаям избегания, практически не принимал никакого участия в раннем воспитании детей. Однако с 8-10 лет мальчики переходили под его опеку, отдаляясь тем самым от матери и сестёр; тогда как девочки до своего замужества продолжали находиться под присмотром женщин. В дальнейшем отцу запрещалось вести весёлые разговоры и шутить с дочерьми. $\mathrm{C}$ ними, как говорили нивхи, можно было только серчать и вести серьёзные разговоры. Запретов на общение с матерью для сыновей, а тем более дочерей не было [16, с. 138; 20, с. 187]. Однако современные негидальцы, например, считают, что руки ребенку целовать нельзя - всё трогать будет; ноги ребенку целовать нельзя - душа обидится (Архив ИИАЭНДВ ДВО РАН. Ф. 1. Оп. 2. Д. 599. Т. 2. Л. 222-223).

Интересно отметить, что обычаи избегания между целым рядом близких родственников приводили к тому, что представители малых народов при встречах и расставаниях не здоровались и не прощались.

Вышеизложенный материал позволяет сделать некоторые выводы. Во-первых, ограничения устанавливались преимущественно для женщины в её отношениях к родственникам мужа, и в меньшей степени для мужчины в отношениях к родственникам жены. Во-вторых, ограничения для жены в отношениях к родственникам мужа были существеннее и строже, чем к родственницам, распространяясь в первом случае на больший круг лиц, что вполне объяснимо при той роли, которую играли в семье мужчины и женщины. В-третьих, ограничения, прежде всего, прилагались к старшим родственникам мужа или жены, коими являлись мужчины. Поэтому как муж, так и жена должны были одинаково придерживаться особых правил поведения, преимущественно по отношению к мужским родственникам друг друга; из женских же почти исключительно только по отношению к наиболее почётным, - к тёще и свекрови $[11$, с. 38]. В-четвёртых, запреты на общение распространялись главным образом на отношения между старшими родственниками и младшими (например, старший брат и младшая сестра, отец и дочь, свёкор и невестка).

По мнению Л.Я. Штернберга, запреты и избегания семейно-брачного порядка были направлены на реализацию установленных половых норм: одни из них на то, чтобы ослабить до последней степени инстинкт ревности, другие - чтобы избежать полового общения между лицами запретных друг другу в брачном отношении категорий. Запреты 1-го ряда - это запреты между лицами одного пола, принадлежавшими к одному классу по групповому браку, в частности, между родными братьями и сёстрами. Запреты второго ряда распространялись на всех лиц другого пола, не принадлежавших к категории потенциальных жён или мужей, в частности, на своих сестёр, сестёр отца и т.п. [21, с. 95- 98]. У нивхов, в силу одностороннего кузенного брака и брачной регламентации, понятия свойства совпадало с понятием когнатного родства, поэтому каждой женщине запрещалось разговаривать с отцом её невестки, так как зачастую этот мужчина являлся её братом, а братья и сёстры у нивхов принадлежали к запретным категориям. Точно также мужчина не мог разговаривать с матерью своего зятя, так как эта женщина, согласно брач- 
ной регламентации, приходилась ему сестрой. Позднее возникли запреты и избегания, связанные не непосредственно с браком, а скорее, уже с семьёй. Таковы, например, обычаи, не позволяющие отцу проявлять заботу о своём сыне при посторонних, а также называть своего ребёнка по имени [6, с. 166].

Характерно, что избегания между женихом и невестой, а впоследствии и между супругами носили более или менее условный характер, они как бы демонстрировались и усиленно подчёркивались перед окружающими, тогда как сами отношения между супругами были окружены тайной [6, с. 170-173]. Наиболее строгими и многочисленными были запреты и избегания между невесткой и свёкром, которые обычно носили пожизненный характер. Следует отметить, что запреты в отношении свекрови по своей строгости и значимости были почти равнозначны запретам по отношению к свёкру. Разница заключалась лишь в том, что запреты по отношению к отцу мужа носили более продолжительный характер и касались различных интимных сторон (нельзя было видеть голые ноги, непокрытую голову и т.д.), что можно объяснить различием полов. В отношении младшей родни мужа (независимо от пола) ограничения были не очень значительными и касались, главным образом, запрета на произнесение имени друг друга. Зять, в свою очередь, своим молчанием показывал глубокое почтение и уважение к родственникам жены. После того, как тесть одаривал его, запреты избегания снимались [6, с. 189]. Отсутствие обычаев избегания между матерью и сыном у нивхов Л.Я. Штернберг объяснял инстинктивным отвращением к половой близости между ними; а между зятем и тёщей тем фрактом, что "невестка обычно переходила в дом свёкра и постоянно с ним встречалась, тогда как зять уводил жену к себе и редко виделся со своей тёщей, потому и их отношения не требовали специального ограничения" [21, с. 97]. Наличие запрета на отношения между зятем и тёщей служит косвенным указанием на пережиток материнского рода и матрилокального поселения, когда мужчина-чужак попадал в род жены [6, с. 235-236].

\section{Литература}

1. Березницкий С.В. Влияние верований и обрядов на формирование культуры традиционного общества коренных народов Приамурья и Сахалина // Обозрение результатов полевых и лабораторных исследований археологов и этнографов Сибири и Дальнего Востока в 1994-1996 годах. Новосибирск: Издательство Института археологии и этнографии СО РАН, 2000. С. 201-203.

2. Гаер E.А. Древние бытовые обряды нанайцев. Хабаровск: Книжное издательство, 1991. 142 с.

3. Гурвич И.С. О современном состоянии традиционных религиозных верований малых народов Севера и пути их преодоления // Вопросы преодоления пережитков прошлого и становление новых обычаев и традиций у народов Сибири: Мат-лы научно-практ. конфр., сост-ся 22-26 ноября 1966 г. в г. Улан-Удэ / Отв. ред. А.П. Окладников, Д.Д. Лубсанов. Вып. 1. Улан-У дэ: Бурятское кн. изд-во, 1968. С. 87-94.

4. Зуев В.Ф. Утро древнего стойбища. Хабаровск: Книжное издательство, 1990. 160 c.

5. История и культура тазов: историко-этнографические очерки (вторая половина XIX - начало XXI вв.) / Отв. ред. А.Ф. Старцев. Владивосток: Дальнаука, 2019. $416 \mathrm{c}$.

6. Кисляков Н.А. Очерки по истории семьи и брака у народов Средней Азии и Казахстана. Л.: Наука, 1969. 240 с.

7. Кого-Самара Н. Охотничий быт нанай // Тайга и тундра: журнал. Л., 1928. № 1. C. 28-32.

8. Крейнович Е.А. Нивхгу: Загадочные обитатели Сахалина и Амура. М.: Наука, 1973. 496 с.

9. Крейнович Е.А. О пережитках группового брака у нивхов // Сб.: Страны и народы Востока. Вып. 15 (Африка и Азия). М., 1973. С. 224-233.

10. Лопатин И.А. Гольды амурские, уссурийские и сунгарийские: Опыт этнографического исследования // Записки ОИАК Владивостокского отделения ПОРГО. Владивосток, 1922. Т. 17. 372 с.

11. Максимов А.Н. Ограничение отношений между одним из супругов и родственниками другого // Этнографическое обозрение. 1908. № 1-2. С. 1-77.

12. Мельникова Т. В. Традиционная одежда нанайцев (XIX - XX в. в.): диссертация ...кандидата истор. наук. Владивосток, 2000. 300 с. 
13. Пилсудский Б.О. Из поездки к орокам о. Сахалина в 1904 г. Препринт. Южно-Сахалинск: ИМГиГ (Институт морской геологии и географии) ДВО АН СССР, 1989. 76 c.

14. Пухта М.Н. О нивхском этикете // Известия Института наследия Бр. Пилсудского. Институт наследия Бр. Пилсудского при Сахалинском государственном областном краеведческом музее. Южно-Сахалинск. Сахалинский областной краеведческий музей, 1999. С. 217-223.

15. Смоляк А.В. Народы Севера и Дальнего Востока //Семейный быт народов СССР. М.: Наука, 1990. С. 307-336.

16. Таксами Ч.М. Основные проблемы этнографрии и истории нивхов: сер. X1X нач. ХХ в. Л.: Наука, 1975. 238 с.

17. Ходжер Г.Г. Конец большого дома. Хабаровск: Книжное издательство, 1969. 368 c.

18. Цинциус В.И. Воззрения негидальцев, связанные с охотничьим промыслом // Сб.: Религиозные представления и обряды народов Сибири в X1X - нач. XX вв. Л.: Наука, 1971. С. 170-200.

19. Шимкевич П.П. Некоторые моменты из жизни гольдов и связанные с жизнью суеверия. // Этнографическое обозрение. 1897. № 3. Кн. 34. С. 1-20.

20. Штернберг Л.Я. Гиляки, орочи, гольды, негидальцы, айны. Хабаровск: Книжное издательство, 1933. 740 с.

21. Штернберг Л.Я. Семья и род у народов Северо-Восточной Азии. Л., 1933. 187 с.

\section{Транслитерация по ГОСТ 7.79-2000 Система Б}

1. Bereznitskij S.V. Vliyanie verovanij i obryadov na formirovanie kul'tury traditsionnogo obshhestva korennykh narodov Priamur'ya i Sakhalina // Obozrenie rezul'tatov polevykh i laboratornykh issledovanij arkheologov i ehtnografov Sibiri i Dal'nego Vostoka v 1994-1996 godakh. Novosibirsk: Izdatel'stvo Instituta arkheologii i ehtnografii SO RAN, 2000. S. 201-203.

2. Gaer E.A. Drevnie bytovye obryady nanajtsev. KHabarovsk: Knizhnoe izdatel'stvo, 1991. 142 s.

3. Gurvich I.S. O sovremennom sostoyanii traditsionnykh religioznykh verovanij malykh narodov Severa i puti ikh preodoleniya // Voprosy preodoleniya perezhitkov proshlogo i stanovlenie novykh obychaev i traditsij u narodov Sibiri: Mat-ly nauchno-prakt. konf., sost-sya 22-26 noyabrya 1966 g. v g. Ulan-Udeh / Otv. red. A.P. Okladnikov, D.D. Lubsanov. Vyp. 1. Ulan-Udeh: Buryatskoe kn. izd-vo, 1968. S. 87-94. $160 \mathrm{~s}$.

4. Zuev V.F. Utro drevnego stojbishha. KHabarovsk: Knizhnoe izdatel'stvo, 1990.

5. Istoriya i kul'tura tazov: istoriko-ehtnograficheskie ocherki (vtoraya polovina XIX - nachalo XXI vv.) / Otv. red. A.F. Startsev. Vladivostok: Dal'nauka, 2019. 416 s.

6. Kislyakov N.A. Ocherki po istorii sem'i i braka u narodov Srednej Azii i Kazakhstana. L.: Nauka, 1969. 240 s.

7. Kogo-Samara N. Okhotnichij byt nanaj // Tajga i tundra: zhurnal. L., 1928. № 1. S. $28-32$.

8. Krejnovich E.A. Nivkhgu: Zagadochnye obitateli Sakhalina i Amura. M.: Nauka, 1973. $496 \mathrm{~s}$.

9. Krejnovich E.A. O perezhitkakh gruppovogo braka u nivkhov // Sb.: Strany i narody Vostoka. Vyp. 15 (Afrika i Aziya). M., 1973. S. 224-233.

10. Lopatin I.A. Gol'dy amurskie, ussurijskie i sungarijskie: Opyt ehtnograficheskogo issledovaniya // Zapiski OIAK Vladivostokskogo otdeleniya PORGO. Vladivostok, 1922. T. $17.372 \mathrm{~s}$.

11. Maksimov A.N. Ogranichenie otnoshenij mezhdu odnim iz suprugov i rodstvennikami drugogo // EHtnograficheskoe obozrenie. 1908. № 1-2. S. 1-77.

12. Mel'nikova T. V. Traditsionnaya odezhda nanajtsev (XIX - XX v. v.): dissertatsiya ...kandidata istor. nauk. Vladivostok, 2000. $300 \mathrm{~s}$.

13. Pilsudskij B.O. Iz poezdki k orokam o. Sakhalina v 1904 g. Preprint. YUzhno-Sakhalinsk: IMGiG (Institut morskoj geologii i geografii) DVO AN SSSR, 1989. 76 s.

14. Pukhta M.N. O nivkhskom ehtikete // Izvestiya Instituta naslediya Br. Pilsudskogo. Institut naslediya Br. Pilsudskogo pri Sakhalinskom gosudarstvennom oblastnom kraevedcheskom muzee. YUzhno-Sakhalinsk. Sakhalinskij oblastnoj kraevedcheskij muzej, 1999. S. 217-223.

15. Smolyak A.V. Narody Severa i Dal'nego Vostoka //Semejnyj byt narodov SSSR. M.: Nauka, 1990. S. 307-336.

16. Taksami CH.M. Osnovnye problemy ehtnografii i istorii nivkhov: ser. KH1KH nach. KHKH v. L.: Nauka, 1975. 238 s.

17. KHodzher G.G. Konets bol'shogo doma. KHabarovsk: Knizhnoe izdatel'stvo, 1969. 368 s. 
18. TSintsius V.I. Vozzreniya negidal'tsev, svyazannye s okhotnich'im promyslom // Sb.: Religioznye predstavleniya i obryady narodov Sibiri v KH1KH - nach. KHKH vv. L.: Nauka, 1971. S. 170-200.

19. SHimkevich P.P. Nekotorye momenty iz zhizni gol'dov i svyazannye s zhizn'yu sueveriya. // EHtnograficheskoe obozrenie. 1897. № 3. Kn. 34. S. 1-20.

20. SHternberg L.YA. Gilyaki, orochi, gol'dy, negidal'tsy, ajny. KHabarovsk: Knizhnoe izdatel'stvo, 1933. $740 \mathrm{~s}$.

21. SHternberg L.YA. Sem'ya i rod u narodov Severo-Vostochnoj Azii. L., 1933. 187 s.

Фадеева Е. В. Обычаи избегания в традиционной семье коренных народов Нижнего Амура и Сахалина: середина XIX - начало XX вв..

В статье путём сравнительно-исторического метода анализируются обычаи избегания между различными категориями родственников и свойственников в традиционной семье коренных народов Нижнего Амура и Сахалина. Представленные материалы позволяют сделать следующие выводы: во-первых, ограничения устанавливались преимущественно для женщины в её отношениях к родственникам мужа, и в меньшей степени для мужчины в отношениях к родственникам жены, что вполне объяснимо при той роли, которую играли в семье мужчины и женщины. Во-вторых, ограничения прежде всего прилагались к старшим родственникам мужа или жены, коими являлись мужчины. В-третьих, запреты на общение распространялись, главным образом, на отношения между старшими родственниками и младшими (например, старший брат и младшая сестра, отец и дочь, свёкор и невестка).

Ключевые слова: коренные этносы, обычаи избегания, запреты, отиовский род, материнский род

Fadeeva E. V. Avoidance customs in the traditional family of the indigenous peoples of the Lower Amur and Sakhalin: mid-XIX - early XX centuries.

The article, using the comparative historical method, analyzes the customs of avoidance between different categories of relatives and relatives in the traditional family of indigenous peoples of Lower Amur and Sakhalin. The materials presented allow us to draw the following conclusions: firstly, restrictions were set mainly for a woman in her relations with her husband's relatives, and to a lesser extent for a man in relations with her wife's relatives, which is quite understandable with the role that men and women played in the family. Secondly, restrictions, first of all, were applied to the elder relatives of the husband or wife, of whom men were. Thirdly, prohibitions on communication extended mainly to relations between older relatives and younger ones (for example, older brother and younger sister, father and daughter, father-in-law and daughter-in-law).

Key words: indigenous ethnic groups, customs of avoidance, prohibitions, paternal clan, maternal gender

Для цитирования: Фадеева Е. В. Обычаи избегания в традиционной семье коренных народов Нижнего Амура и Сахалина: середина XIX - начало XX вв. // Ойкумена. Регионоведческие исследования. 2020. № 4. C. 45-53. DOI: 10.24866/1998-6785/2020-4/45-53

For citation: Fadeeva E. V. Avoidance customs in the traditional family of the indigenous peoples of the Lower Amur and Sakhalin: mid-XIX - early XX centuries // Ojkumena. Regional researches. 2020. № 4. P. 45-53. DOI: 10.24866/1998-6785/2020-4/45-53 